\title{
Insulin Sensitivity Measurement
}

National Cancer Institute

\section{Source}

National Cancer Institute. Insulin Sensitivity Measurement. NCI Thesaurus. Code

C123459.

The determination of the insulin sensitivity (cells are stimulated by lower than normal insulin levels) in a biological specimen. 